\title{
Analysis of Benzene Exposure Levels on Commuters Traveling within the Metropolitan Area of Costa Rica
}

\author{
Wendy Villalobos-Gonzalez¹, Germain Esquivel-Hernandez ${ }^{1,2}{ }^{*}$, Ricardo Sanchez-Murillo², \\ José Leonardo Corrales-Salazar ${ }^{2}$, Juan Valdes-Gonzalez ${ }^{1}$ \\ ${ }^{1}$ Laboratorio de Química de la Atmosfera, Universidad Nacional, Escuela de Química, Heredia, Costa Rica \\ ${ }^{2}$ Grupo de Investigación en Isotopos Estables, Universidad Nacional, Escuela de Química, Heredia, Costa Rica \\ Email: ${ }^{*}$ germain.esquivel.hernandez@una.cr
}

Received 28 February 2015; accepted 12 March 2015; published 24 March 2015

Copyright (C) 2015 by authors and Scientific Research Publishing Inc.

This work is licensed under the Creative Commons Attribution International License (CC BY). http://creativecommons.org/licenses/by/4.0/

(c) (i) Open Access

\section{Abstract}

This study reports the benzene exposure levels of commuters traveling within the metropolitan area of Costa Rica using personal cars, buses, and urban trains. 47 in-vehicle samples were collected in the 2014 wet season under three different driving conditions: rush hour traffic, normal traffic and weekends. Samples were collected in Tedlar bags and analyzed using $75 \mu \mathrm{m}$ carboxenpolydimethylsiloxane (CAR/PDMS) and gas chromatography with flame ionization detection (GCFID). Additionally, duplicate samples were collected on adsorption tubes filled with Tenax TA and analyzed by thermal desorption (TD) and GC-FID. Results indicate that travelling in cars and buses under rush hour conditions exposes commuters to statistically equal average benzene concentration of 48.7 and $51.6 \mu \mathrm{g} / \mathrm{m}^{3}$, respectively. Average benzene levels in urban trains $\left(33.0 \mu \mathrm{g} / \mathrm{m}^{3}\right)$ were measured only during morning rush hours. Greater benzene levels in buses than personal cars concentrations may be attributable to the immersion of traffic-related emission within the bus cabins. Factors, such as the driving pattern, the number of vehicles on the route, the road infrastructure, and the prevalence of gasoline-fueled vehicles in Costa Rica, may increase ambient benzene concentrations. Benzene levels inside car cabins reported in this study are in the range of those reported in other urban areas; however, the corresponding concentrations inside buses and urban trains (rush hour only) are higher than previously published exposure levels.

\section{Keywords}

Costa Rica, Benzene Exposure Levels, Solid Phase Microextraction (SPME), Traffic Hours, Commuters Exposure

\footnotetext{
${ }^{*}$ Corresponding author.
}

How to cite this paper: Villalobos-Gonzalez, W., Esquivel-Hernandez, G., Sanchez-Murillo, R., Corrales-Salazar, J.L. and Valdes-Gonzalez, J. (2015) Analysis of Benzene Exposure Levels on Commuters Traveling within the Metropolitan Area of Costa Rica. Open Journal of Air Pollution, 4, 38-46. http://dx.doi.org/10.4236/ojap.2015.41005 


\section{Introduction}

In past years, the exposure levels of commuters to volatile organic compounds (VOCs) inside public transport modes have been reported in several urban locations in Europe, Asia and megacities such as Mexico City [1]-[4]. These studies have raised interest and serious concern about the impact of organic compounds emitted by automotive traffic on human health and air quality, which is now recognized as a major environmental problem in urban areas [5]-[7]. The available information indicates that commuting can cause elevated personal exposure to toxic VOCs, including compounds known as carcinogenic such as benzene, which is closely linked to the induction of leukemia [8] [9]. In contrast to the number of studies carried out in developed countries and highly populated cities, such investigations are scarce in Latin-American countries [10], where similar to other regions, the rapid development and rapid urbanization have increased the traffic-related air pollution, which turns into an urgent need to gather information for future transport and urban healthcare planning [4] [5] [8].

In Costa Rica, the metropolitan area is located in the center of the country within a volcanic-originated plateau of approximately $3000 \mathrm{~km}^{2}$. The Costa Rican Central Valley has an average elevation of $1100 \mathrm{~m}$ a.s.l and contains about $75 \%$ of the country's vehicle fleet (approximately 734,200 units), $65 \%$ of domestic industry and $60 \%$ of Costa Rica's population ( $2,580,000$ habitants) [11]. Although the distance between the four major cities in the metropolitan area, namely Heredia, San Jose, Alajuela and Cartago, is only $10-20 \mathrm{~km}$, the available road system is characterized by a slow-moving traffic pattern, especially during the rush hours (6:00 a.m. to 9:00 a.m.) in the morning and the afternoon (4:00 p.m. to 6:00 p.m.), which increases the amounts of vehicle-related pollutants emitted into the air. Under these driving conditions, the stop-and-go traffic adversely affects the in-vehicle air quality, and increases the exposure of commuters to higher VOCs levels [4] [8].

Traditionally, the analysis of VOCs includes the use of solid adsorbents to concentrate the VOCs, followed by analyte transfer through either thermal desorption or solvent extraction into a gas chromatography system [1] [10]. Solid-phase microextraction (SPME) techniques have proven to be very useful tools in the analysis of wide VOCs in the air. SPME has been applied to the analysis of benzene and other VOCs in workplace and ambient air, and also to the analysis of the highly reactive sesquiterpene and oxygenated terpene compounds emitted by live vegetation [12] [13].

The aim of this study is to measure the levels of exposure of commuters to benzene in the public transportation means (personal cars, buses, and urban trains) that are used to travel in the metropolitan area of Costa Rica, using solid-phase microextraction. The studied transportation routes cover an important traffic zone that enters San Jose from the north and urban areas that include the downtown of Heredia and San Jose, the surrounding commercial and business areas, and also one of the three available urban train connections so far in Costa Rica.

\section{Materials and Methods}

\subsection{Transport Modes and Sampling Routes}

Benzene measurements were conducted in personal cars, buses, and urban trains travelling the $12-14 \mathrm{~km}$ route from Heredia to San Jose. A map of the study routes is shown in Figure 1. The corresponding description of the sampling routes is summarized in Table 1.

Personal vehicle and bus samples were taken in each direction from the main station in Heredia and the main station in San Jose, located in the Central District. This route uses the Pan-American Highway to enter San Jose, travelling ca. $4 \mathrm{~km}$ on this highway (Figure 1). In Costa Rica, most buses and cars are driven with open windows and no A/C system is used during commuting. Therefore, all samples were collected under these conditions. Sampling trips were made on catalyst cars and buses using gasoline and diesel, respectively, manufactured after 1990 (cars) and 2000 (buses).

The urban train fleet travelling in Costa Rica is fueled by diesel. Similar to the sampling conducted inside cars and buses, urban train sampling was carried out in units that travelled with open windows and no $\mathrm{A} / \mathrm{C}$ system. The urban train route reaches San Jose downtown about $2 \mathrm{~km}$ northeast from the bus station located in Central District, after travelling on the outskirts Heredia and San Jose, northeast San Jose (Figure 1).

\subsection{Sampling Methods}

Sampling was conducted during July, August, and September 2014. Samples were collected under three different conditions: morning rush hours (07:00 to 09:00), normal traffic (09:00 to 15:00) and weekends. Six air sam- 


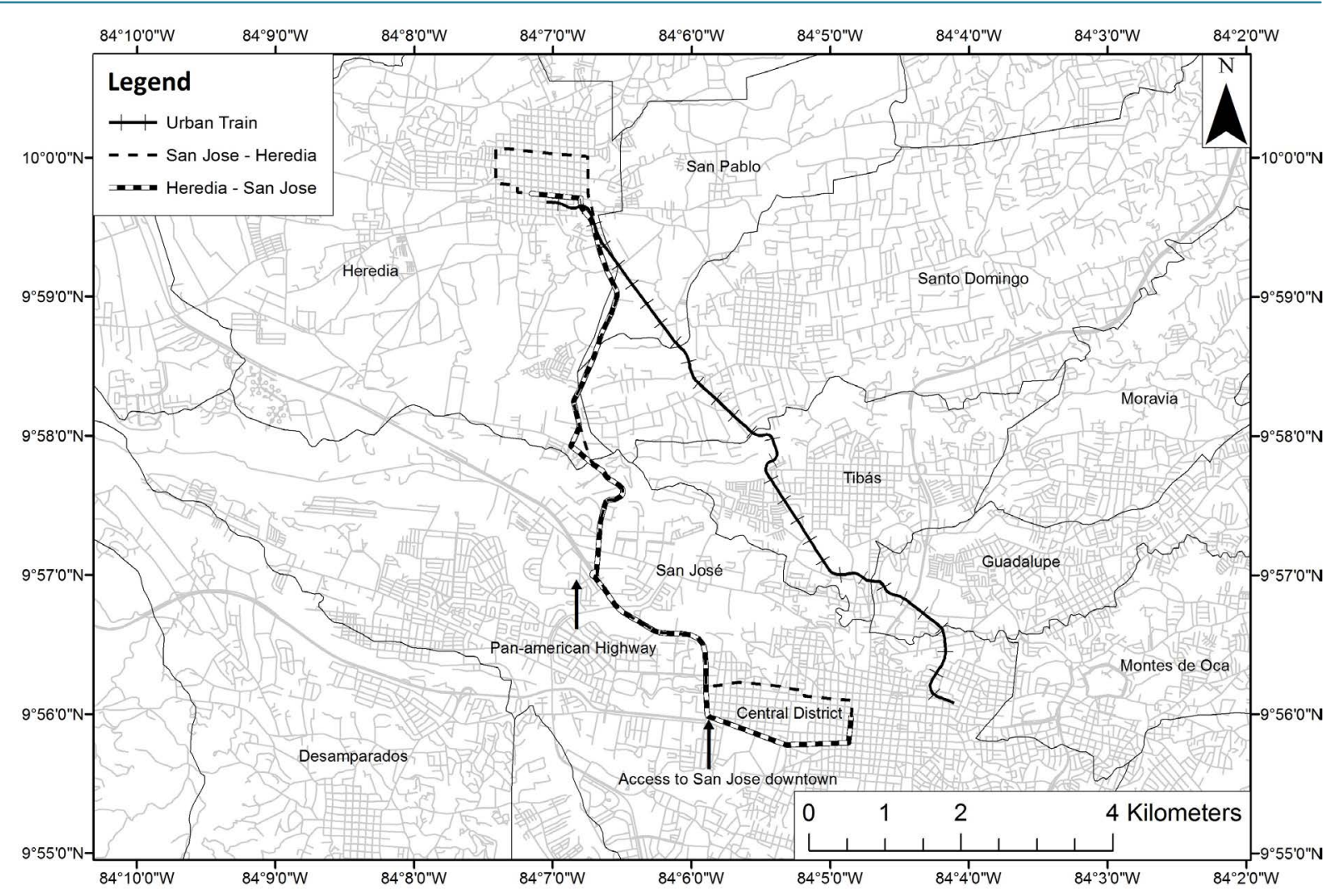

Figure 1. Map of the study area showing the sampling routes. Benzene measurements in personal vehicles and buses were conducted on the routes Heredia-San Jose and San Jose-Heredia.

Table 1. Description of the sampling routes.

\begin{tabular}{|c|c|c|c|}
\hline Transport mode & Route & Trip duration (min) & Route characteristics \\
\hline Urban train & Heredia-San Jose & 26 (rush hour) & $\begin{array}{l}\text { This } 14 \mathrm{~km} \text { route runs from Heredia downtown to San } \\
\text { Jose west district, crossing residential areas located at } \\
\text { the outskirts both cities. }\end{array}$ \\
\hline Bus & Heredia-San Jose (highway) & $\begin{array}{l}44 \text { (rush hour) } \\
37 \text { (normal traffic) } \\
36 \text { (weekends) }\end{array}$ & \multirow{2}{*}{$\begin{array}{l}\text { A } 12 \mathrm{~km} \text { route, running from Heredia downtown to } \\
\text { San Jose central district, crossing industrial areas and } \\
\text { using the Pan-American highway to enter San Jose. }\end{array}$} \\
\hline Personal vehicle & Heredia-San Jose (highway) & $\begin{array}{l}51 \text { (rush hour) } \\
39 \text { (normal traffic) } \\
35 \text { (weekends) }\end{array}$ & \\
\hline
\end{tabular}

ples were collected inside buses and cars during rush hour, while during normal traffic and weekends the number of samples was increased to seven. At the time this study was carried out, the urban train service was only available during the rush hours in the morning and the afternoon. Inside this transport mode, the number of samples collected was seven samples. No samples were collected during the afternoon rush hour in order to avoid rainy conditions, which is a typical weather condition after noon in the Central Valley of Costa Rica on JulySeptember. The average temperature range was between $19.5^{\circ} \mathrm{C}$ and $28.7^{\circ} \mathrm{C}$. The average wind direction was from southeast $\left(109^{\circ}\right)$ with an average speed of $1.9 \mathrm{~m} / \mathrm{s}$.

SPME samples were collected using 2 - 5 L Tedlar bags, which were filled by using a SKC model 222-2301 air pump, operating at a flow of $100-500 \mathrm{~mL} / \mathrm{min}$. For comparison purposes, 8 samples were simultaneously analyzed by SPME and adsorption tubes followed by thermal desorption. Duplicates samples were collected using adsorption cartridges filled with Tenax TA, and precision air pumps (A.P. Buck, FL, USA). The air samples volume was in the range from 1.0 to $2.0 \mathrm{~L}$. 


\subsection{Gas Chromatographic Analysis}

The efficiency of organic compounds extraction by SPME is mainly controlled by the fiber properties and the experimental conditions [14]. Some authors have reported the use of PDMS fibers with the addition of a carbon sorbent (CAR/PDMS), which led to more effective trapping of volatile compounds [12] [15]. Therefore, benzene was extracted using SPME Carboxen-PDMS (CAR/PDMS), $75 \mu \mathrm{m}$ film thickness, fibers (Supelco, PA, USA), in order to achieve a higher efficiency in the concentration step. SPME fibers were inserted into the Tedlar bags for 20 minutes to extract the VOCs, and then were inserted for 5 minutes inside the injector port of a Perkin Elmer Autosystem XL chromatograph and desorbed at $250^{\circ} \mathrm{C}$ (Perkin Elmer Instruments, MA, USA). VOCs were separated using a DB-1 capillary column, $30 \mathrm{~m}$ long $\times 0.32 \mathrm{~mm}$ internal diameter $\times 3.0 \mu \mathrm{m}$ film thickness. VOCs were eluted with helium, raising temperature from $30^{\circ} \mathrm{C}$ to $200^{\circ} \mathrm{C}$ at $8.5^{\circ} \mathrm{C} / \mathrm{min}$. Adsorption tubes samples were analyzed using thermal desorption combined with gas chromatography. VOCs were extracted at $250^{\circ} \mathrm{C}$ for 10 minutes and then separated using a DB-1 capillary column, $60 \mathrm{~m}$ long $\times 0.32 \mathrm{~mm}$ internal diameter $\times 1.0 \mu \mathrm{m}$ film thickness. VOC's were desorbed onto the cooled column and eluted with helium, raising temperature from $-60^{\circ} \mathrm{C}$ to $200^{\circ} \mathrm{C}$ at $8.5^{\circ} \mathrm{C} / \mathrm{min}$. For both the SPME and adsorption tubes analysis, the detection was accomplished using a FID detector. Qualitative analysis of benzene was made based on retention data and comparison with known composition samples.

Both the SPME and adsorption cartridges systems were calibrated using standards generated by a home-built capillary diffusion system. The diffusion device was filled with neat liquid benzene (p.a, J.T. Baker, PA, USA). A description of this methodology has been recently described by Thorenz et al. [16]. Standards were prepared in the range $15-100 \mu \mathrm{g} / \mathrm{m}^{3}$ using a dynamic dilutor and a zero air generator. SPME standards were prepared in 2 - 5 L Tedlar bags, whereas the adsorption tubes standards were prepared by sampling directly the air generated by the dynamic dilutor using a precision pump. The detection limit of benzene for SPME method, defined as the amount of standard required to produce a peak three times the baseline noise, was defined on $0.01 \mu \mathrm{g} / \mathrm{m}^{3}$. The analytical precision of the SPME method was better than $2.0 \%$, expressed as relative standard deviation.

\section{Results and Discussion}

\subsection{SPME Method}

The chromatogram in Figure 2(a) reflects the averaged composition of ambient air inside a private car during a representative commuter trip. The chromatogram shows the typical analytical separation of VOCs collected from urban ambient air, where the alkylbenzenes and n-alkanes are major components of traffic-polluted air [1]. A good linearity was achieved for benzene calibration using SPME, as shown in Figure 2(b). Sources of random error include the flow controllers used for benzene dilutions, the temperature control of the diffusion system and the use of different fibers during the analysis of samples and standards.

Quantitation of benzene by adsorption tubes in samples that were collected in duplicates with Tedlar bags, correlated well with the benzene levels calculated with SPME (slope $=1.43 \pm 0.66, \mathrm{r}^{2}=0.82$ ), as shown in Figure 3.

\subsection{In-Vehicle Benzene Levels}

The concentration of benzene measured inside the car and bus varied considerably with the driving conditions. As shown in Figure 4, benzene levels were found to be greater inside the bus than inside the car. However, under the rush hour condition, there is no statistical significant difference at $95 \%$ confidence $(p=0.32)$, between the average benzene concentration inside cars $\left(48.7 \pm 10.8 \mu \mathrm{g} / \mathrm{m}^{3}\right)$ and buses $\left(51.6 \pm 10.5 \mu \mathrm{g} / \mathrm{m}^{3}\right)$. The decreasing levels shown suggest that driving conditions might influence the in-vehicle VOCs levels in relation with the amount of vehicles travelling along the route, as the exposure levels associated with driving under each condition were statistical significant different for both buses and personal vehicles ( $p$ values $<0.05$ ). This finding, where the exposure level inside both cars and buses was lower in normal traffic hour than in rush hour, can be explained by the fact that the travel time was reduced in 12 minutes for cars and 8 minutes for buses (Table 1). This reduced the exposure time, and at the same time, a decreasing number of vehicles travelled on the route during this time of day. On weekends, the main factor controlling the exposure levels seems to be in fact the traffic volume.

In-train average benzene level $\left(33.0 \pm 12.7 \mu \mathrm{g} / \mathrm{m}^{3}\right)$ is relative greater than those reported for similar transport 


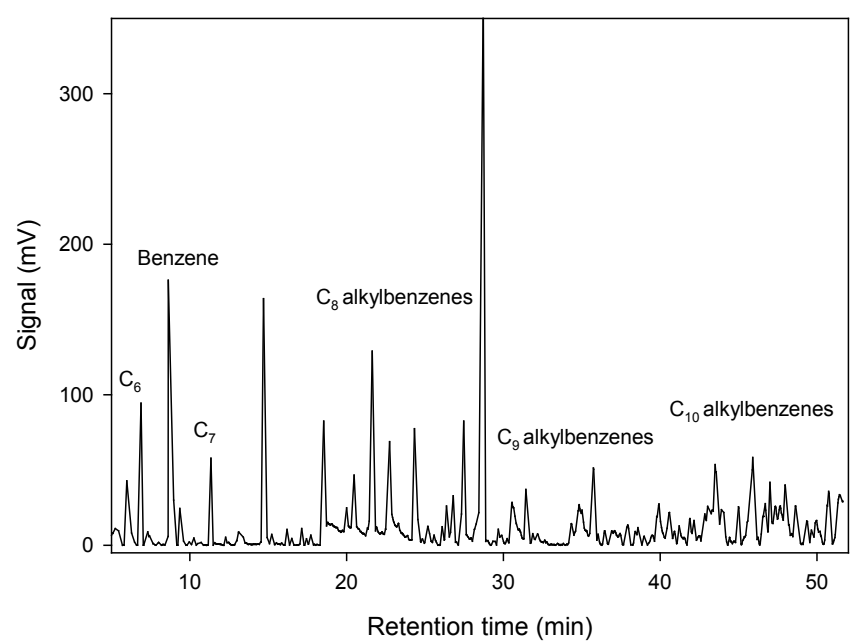

(a)

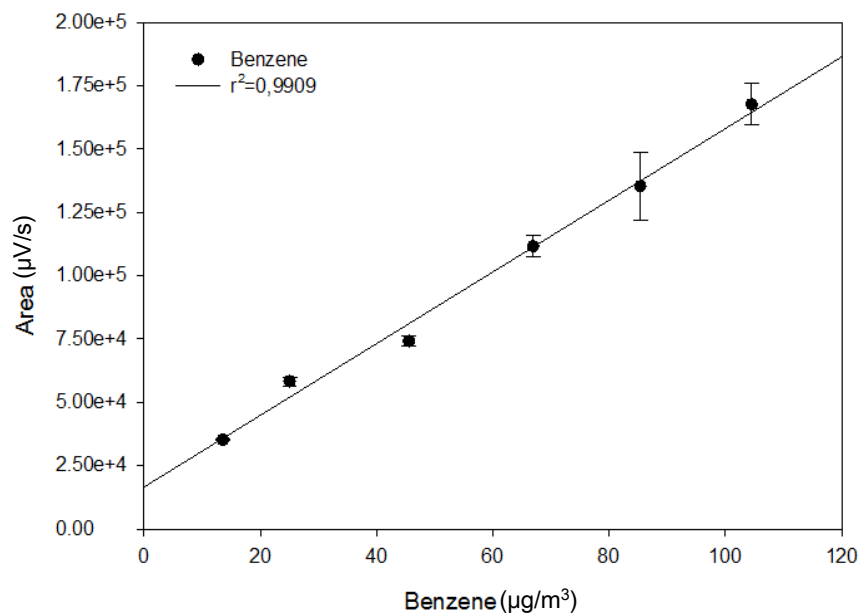

(b)

Figure 2. SPME analysis of benzene: (a) the chromatogram from an ambient air sample collected inside a private vehicle under rush hour conditions; (b) an example of a calibration curve constructed from benzene standards used to calculate benzene concentrations.

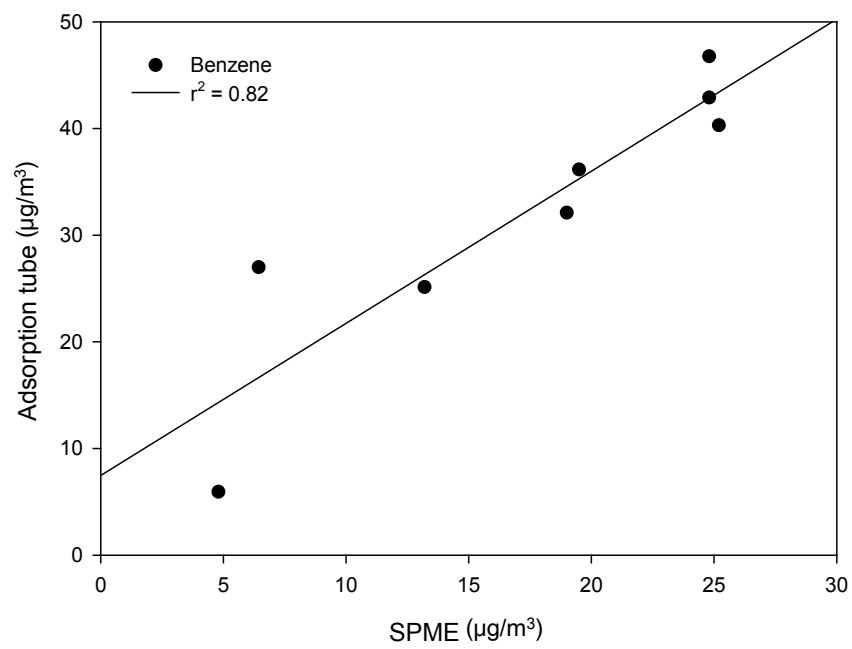

Figure 3. Correlation analysis for benzene concentrations measured using adsorption tubes and SPME $(\mathrm{n}=8)$. 


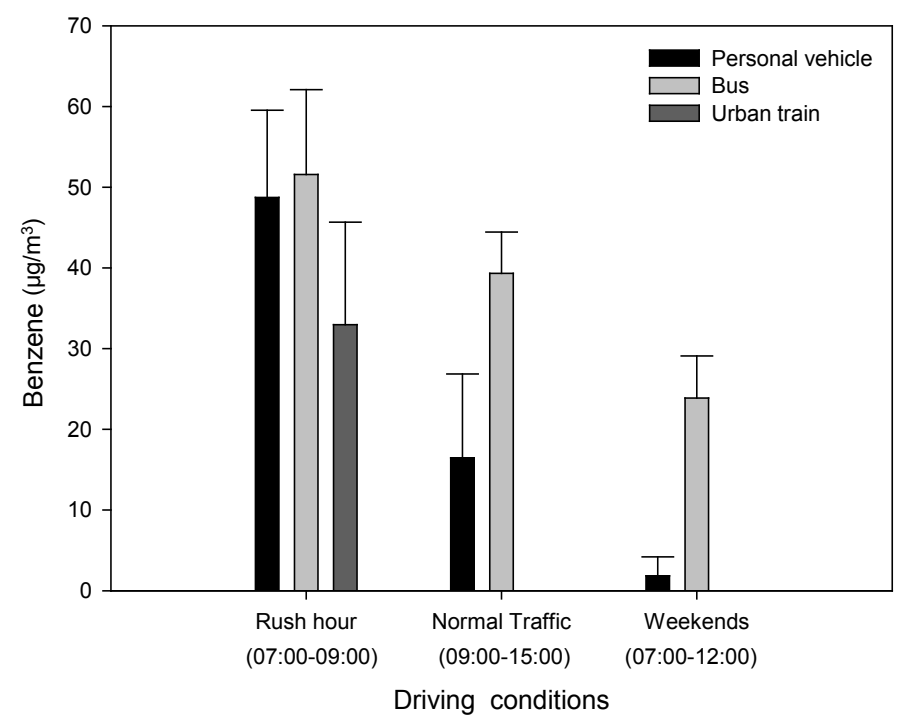

Figure 4. Comparison of average benzene concentrations measured inside the transport modes under different driving conditions. Uncertainty shown was calculated as one standard deviation of measured levels.

modes in other cities [3] [4] [9], where in-train benzene levels were below $15.0 \mu \mathrm{g} / \mathrm{m}^{3}$. This may be attributable to the fact that emissions from cars and buses driving in the nearby streets may eventually be transported to the railroad and reach the train cabin. Another possibility is that measured benzene levels indicate self-contamination arising from the train engine emissions. However, because there are no data available for normal traffic hours and weekends, this value cannot be used to discuss the influence of driving conditions on this transport mode.

\subsection{Influence of Driving Conditions on In-Vehicle Benzene Levels}

Several authors have reported higher VOCs levels inside cars than other transport modes [8] [9] [17]. These results indicate that VOCs levels inside cars are influenced by self-contamination, as a result of the engine evaporative emissions and vehicle exhaust emissions (Chan et al. 2003). Another source of contamination can be attributable to the exhaust emissions of the surrounding vehicles, which is called "tunnel of pollutants" [9]. Other vehicles, for example buses, use diesel as fuel. Inside these vehicles, VOCs levels are mainly influenced by the penetration of outside air into the cabin [18].

In Costa Rica, the vehicle fleet is composed by $75 \%$ gasoline-fueled vehicles [19]. Therefore, buses travelling in slow-moving traffic pattern may be impacted by surrounding traffic emissions of personal cars, leading to increased VOCs levels inside these transport modes. As shown in Figure 5, under stop and go driving conditions (rush hour), in-car and in-bus benzene levels were similar. Under this condition, exposure to benzene during commuting was statistically equal under rush hours conditions, but significantly different on normal traffic hours and weekends. During rush hours, average driving speed never exceeded $22 \mathrm{~km} / \mathrm{h}$. During normal traffic hours and weekends, average driving speed increased to a maximum of $27 \mathrm{~km} / \mathrm{h}$. However, in car and in-bus levels seems to be affected by the surrounding environment, i.e. the number of vehicles on the route, instead by the driving speed. The lower benzene levels inside cars than in buses may be related with the driving pattern of both transport modes. While buses stop along route to allow commuters to get in and out of the vehicle, cars can drive at a more steady speed during normal traffic hours and weekends, reducing the penetration of outside air in the vehicle. Another explanation may be the road characteristics. In Costa Rica, most streets are designed as two lane narrow roads. In such roads, buses and cars drive on the same lane, exposing commuters to the mixture of VOCs emitted majorly from gasoline combustion. In the study route, about $70 \%$ of the route is composed by such roads, especially in Heredia and San Jose downtown, where the driving speed is relative slow.

\subsection{Comparison with International Studies}

Table 2 shows a comparison of in-vehicle benzene levels in current study with international investigations. To 

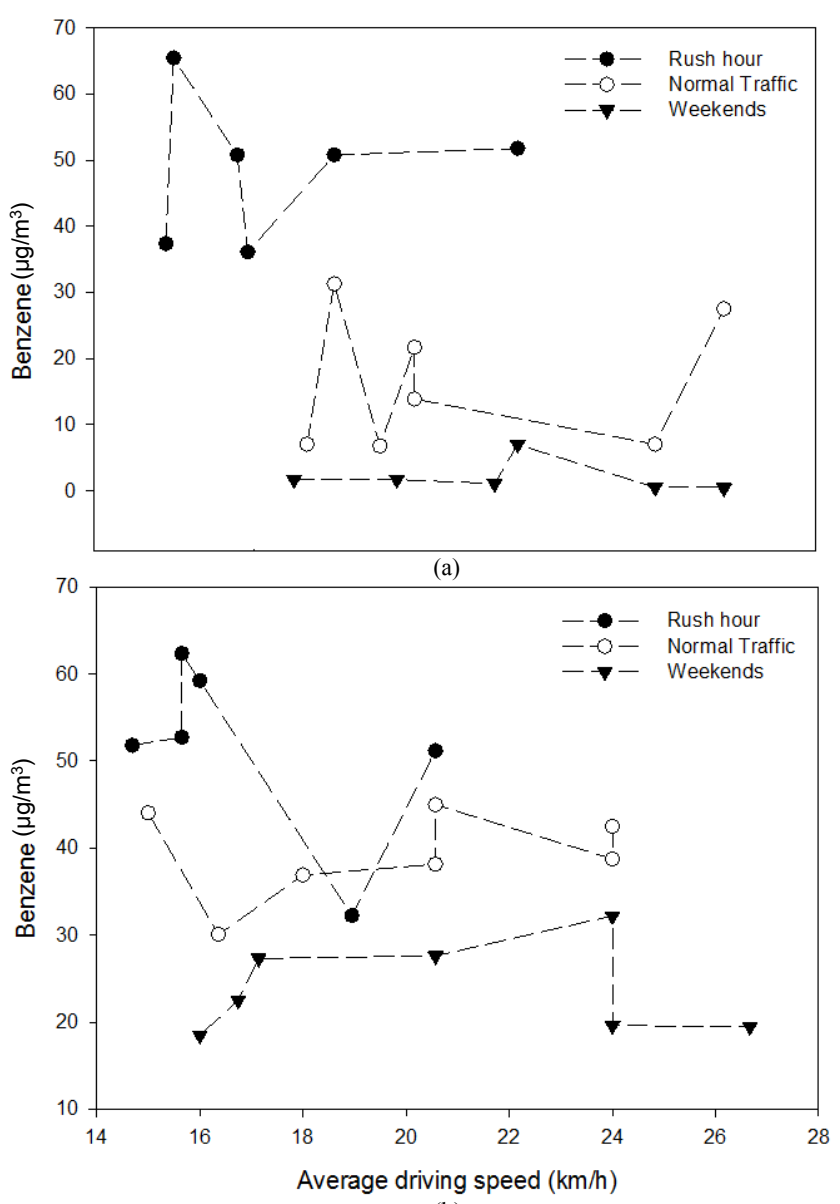

(b)

Figure 5. Influence of average driving speed on benzene concentrations measured inside (a) personal vehicles and (b) buses.

Table 2. Comparison with international studies carried out after 2000.

\begin{tabular}{|c|c|c|c|}
\hline Study & Location & Transport & In vehicle benzene mean concentration $\left(\mu \mathrm{g} / \mathrm{m}^{3}\right)$ \\
\hline \multirow{4}{*}{ This study } & \multirow{4}{*}{ Central Valley, Costa Rica } & Personal car & 22.3 \\
\hline & & Non-A/C bus & 38.3 \\
\hline & & Urban train & 33.0 \\
\hline & & Minibus & 22.3 \\
\hline \multirow[t]{3}{*}{ Gomez-Perales et al. (2001) } & \multirow[t]{3}{*}{ Mexico City } & Bus & 19.1 \\
\hline & & Metro & 12.8 \\
\hline & & Subway & 7.6 \\
\hline \multirow{4}{*}{ Chan et al. (2003) } & \multirow{4}{*}{ Guangzhou, China } & Taxi & 33.6 \\
\hline & & Non-A/C bus & 11.3 \\
\hline & & $\mathrm{A} / \mathrm{C}$ bus & 13.5 \\
\hline & & Car & 39.2 \\
\hline \multirow[t]{2}{*}{ Chertok et al. (2004) } & \multirow[t]{2}{*}{ Sydney, Australia } & Bus & 22.1 \\
\hline & & Train & 12.0 \\
\hline O’Donoghue et al. (2007) & Dublin, Ireland & Bus & 7.0 \\
\hline \multirow{3}{*}{$\begin{array}{l}\text { Ongwandee and Chavalparit, } \\
\qquad(2010)\end{array}$} & \multirow{3}{*}{ Bangkok, Thailand } & $\mathrm{A} / \mathrm{C}$ bus & 39.1 \\
\hline & & Non-A/C bus & 57.1 \\
\hline & & Sky train & 13.2 \\
\hline
\end{tabular}

Sources: [3] [4] [8] [9] [20]. 
our knowledge, there is no available information about VOCs exposure levels inside transport modes in Central American urban areas. In general, average in-car benzene levels in this study were similar to those reported for other studies, where benzene concentration was in the range $30-40 \mu \mathrm{g} / \mathrm{m}^{3}$. However, in-bus and in-train benzene levels are greater than those reported in the selected studies, except for the in-bus levels reported in Bangkok [4]. Regarding levels measured in urban trains, it is difficult to make a direct comparison with other studies, as different study designs and driving conditions were present in the current study. For example, in-train levels reported in this study were only measured in rush hours, with the available train service travelling on groundlevel railroads, unlike the subway and service available in Mexico City and Guangzhou, and the sky train system of Bangkok. Meteorological conditions and other related conditions, like driving with car's window open and the A/C turned off, may also influence our results with respect other studies [8].

\section{Conclusions}

This work reported the exposure levels of traffic-related benzene in three transport modes while driving in the urban area of Costa Rica. Using SPME as analytical technique to measure benzene concentrations in urban air samples proved to be competitive with traditional adsorption tube method and demonstrated to be a rapid and simple analytical tool for the analysis of VOCs. The in-vehicle benzene concentration was influenced by the driving conditions and the transport mode. Exposure to benzene during commuting in cars and buses was statistically equal under rush hours conditions, but significantly different on normal traffic hours and weekends. Passengers of buses were exposed to higher benzene levels during commuting than car and train commuters. Differences may be related with the driving pattern of buses, road characteristics and the prevalence of gasolinefueled vehicles in Costa Rica. In this study, the influence of driving speed on the exposure levels is not clear, however, increasing commuting times will definitely increase the exposure to traffic-related emissions in the three transport modes.

As this preliminary study only includes a limited set of samples collected in the rainy season of 2014, in-vehicle benzene levels can only be used as indicative and as a reference for future studies that may include also other VOCs. Future sampling designs should take into account not studied factors in this study, such as the use of A/C in private vehicles, the driving with closed windows, vehicle's age and fuel type.

\section{Acknowledgements}

Authors would like to thank the personnel of Laboratorio de Química de la Atmósfera for their assistance with air samples collection in this study.

\section{References}

[1] Löfgren, L., Persson, K. and Petersson G. (1991) Exposure of Commuters to Volatile Aromatic Hydrocarbons of Petrol Exhaust. Science of the Total Environment, 108, 225-233. http://dx.doi.org/10.1016/0048-9697(91)90359-M

[2] Barrefors, G. and Petersson, G. (1996) Exposure to Volatile Hydrocarbons in Commuter Trains and Diesel Buses. EnvironmentalTechnology, 17, 643-647. http://dx.doi.org/10.1080/09593331708616429

[3] Gomez-Perales, J.E., Colvilea, R.N., Nieuwenhuijsena, M.J., Fernandez-Bremauntz, A., Gutierrez-Avedoy, V.J., Paramo-Figueroa, V.H., Blanco-Jimenez, S., Bueno-Lopez, E., Mandujanoc, F., Bernabe-Cabanillas, R. and OrtizSegovia, E. (2003) Commuters' Exposure to $\mathrm{PM}_{2.5}$, CO, and Benzene in Public Transport in the Metropolitan Area of Mexico City. Atmospheric Environment, 38, 1219-1229. http://dx.doi.org/10.1016/i.atmosenv.2003.11.008

[4] Ongwandee, M. and Chavalparit, O. (2010) Commuter Exposure to BTEX in Public Transportation Modes in Bangkok, Thailand. Journal of Environmental Sciences, 22, 397-404. http://dx.doi.org/10.1016/S1001-0742(09)60121-2

[5] Rivett, A.C., Martin, D., Gray, D.J., Price, C.S., Nickless, G., Simmonds, P.G., O’Doherty, S.J., Greally, B.R., Knights, A. and Shallcross, D.E. (2003) The Role of Volatile Organic Compounds in the Polluted Urban Atmosphere of Bristol, UK. Atmospheric Chemistry and Physics Discussions, 3, 769-796. http://dx.doi.org/10.5194/acpd-3-769-2003

[6] Steinemann, A. (2004) Human Exposure, Health Hazards, and Environmental Regulations. Environmental Impact Assessment Review, 24, 695-710. http://dx.doi.org/10.1016/j.eiar.2004.06.002

[7] Zhao, L., Wang, X., He, Q., Wanga, H., Sheng, G., Chanb, L.Y., Fua, J. and Blake, D.R. (2004) Exposure to Hazardous Volatile Organic Compounds, $\mathrm{PM}_{10}$ and $\mathrm{CO}$ While Walking along Streets in Urban Guangzhou, China. Atmospheric Environment, 38, 6177-6184. http://dx.doi.org/10.1016/j.atmosenv.2004.07.025

[8] Chan, L.Y., Lau, W.L., Wang, X.M. and Tang, J.H. (2003) Preliminary Measurements of Aromatic VOCs in Public 
Transportation Modes in Guangzhou, China. Environment International, 29, 429-435 http://dx.doi.org/10.1016/S0160-4120(02)00189-7

[9] Chertok, M. (2004) Comparison of Air Pollution Exposure for Five Commuting Modes in Sydney - Car, Train, Autobus, Bicycle and Walking. Health Promotion Journal of Australia, 15, 63-67.

[10] Esquivel-Hernandez, G., Sibaja-Brenes, J.P., Mora-Barrantes, J.C. and Valdes-Gonzalez, J. (2014) First Measurements of Methyl Tert-Butyl Ether (MTBE) in the Ambient Air in San Jose, Costa Rica. WIT Transactions on Ecology and the Environment, Environmental Impact II, 181, 435-442. http://dx.doi.org/10.2495/EID140371

[11] Herrera, J., Rodriguez, S. and Baez, A.P. (2009) Chemical Composition of Bulk Precipitation in the Metropolitan Area of Costa Rica, Central America. Atmospheric Research, 94, 151-160. http://dx.doi.org/10.1016/j.atmosres.2009.05.004

[12] Lee, J., Man Hwang, S., Woon, D. and Suk Heo, G. (2002) Determination of Volatile Organic Compounds (VOCs) Using Tedlar Bag/Solid-Phase Microextraction/Gas Chromatography/Mass Spectrometry (SPME/GC/MS) in Ambient and Workplace. Air Bulletin of Korean Chemistry Society, 23, 488-496. http://dx.doi.org/10.5012/bkcs.2002.23.3.488

[13] Bouvier-Brown, B.C., Holzinger, R., Palitzsch, K. and Goldstein, A.H. (2007) Quantifying Sesquiterpene and Oxygenated Terpene Emissions from Live Vegetation Using Solid-Phase Microextraction Fibers. Journal of Chromatography (A), 1161, 113-120. http://dx.doi.org/10.1016/j.chroma.2007.05.094

[14] Pawliszyn, J. (1997) Solid Phase Microextraction, Theory and Practice. Wiley-VCH, New York.

[15] Isidorov, V.A., Vinogorova, V.T. and Rafalowski, K. (2003) HS-SPME Analysis of Volatile Organic Compounds of Coniferous Needle Litter. Atmospheric Environment, 37, 4645-4650. http://dx.doi.org/10.1016/j.atmosenv.2003.07.005

[16] Thorenz, R., Kundel, M., Muller, L. and Hoffman, T. (2012) Generation of Standard Gas Mixtures of Halogenated, Aliphatic, and Aromatic Compounds and Prediction of the Individual Output Rates Based on Molecular Formula and Boiling Point. Analytical and BioanalyticalChemistry, 404, 2177-2183. http://dx.doi.org/10.1007/s00216-012-6202-5

[17] Leung, P.L. and Harrison, R.M. (1999) Roadside and In-Vehicle Concentrations of Monoaromatic Hydrocarbons. Atmospheric Environment, 33, 191-204. http://dx.doi.org/10.1016/S1352-2310(98)00147-2

[18] Jo, W.K. and Yu, C.H. (2001) Public Bus and Taxicab Driver's Exposure to Aromatic Work-Time Volatile Organic Compounds. Environmental Research Section (A), 86, 66-72. http://dx.doi.org/10.1006/enrs.2001.4257

[19] Direccion General de Calidad Ambiental (2007) http://www.digeca.go.cr/documentos/sustancias\%20quimicas/Capitulo\%201\%20COPs\%20noviembre.pdf.

[20] O’Donoghue, R.T., Gill, L.W., McKevitt, R.J. and Broderick, B. (2007) Exposure to Hydrocarbon Concentrations While Commuting or Exercising in Dublin. Environment International, 33, 1-8. http://dx.doi.org/10.1016/j.envint.2006.05.005 